\title{
A Dual Band Slotted Patch Antenna on Dielectric Material Substrate
}

\author{
M. Habib Ullah, ${ }^{1,2}$ M. T. Islam, ${ }^{2}$ M. R. Ahsan, ${ }^{1,2}$ J. S. Mandeep, ${ }^{2}$ and N. Misran ${ }^{2}$ \\ ${ }^{1}$ Department of Electrical, Electronic and System Engineering, Faculty of Engineering and Built Environment, \\ Universiti Kebangsaan Malaysia (UKM), 43600 Bangi, Selangor, Malaysia \\ ${ }^{2}$ Institute of Space Science (ANGKASA), Universiti Kebangsaan Malaysia (UKM), 43600 Bangi, Selangor, Malaysia \\ Correspondence should be addressed to M. Habib Ullah; habib_ctg@yahoo.com
}

Received 4 October 2013; Accepted 2 November 2013; Published 28 January 2014

Academic Editor: Rezaul Azim

Copyright (C) 2014 M. Habib Ullah et al. This is an open access article distributed under the Creative Commons Attribution License, which permits unrestricted use, distribution, and reproduction in any medium, provided the original work is properly cited.

\begin{abstract}
A low profile, compact dual band slotted patch antenna has been designed using finite element method-based high frequency fullwave electromagnetic simulator. The proposed antenna fabricated using LPKF printed circuit board (PCB) fabrication machine on fiberglass reinforced epoxy polymer resin material substrate and the performance of the prototype has been measured in a standard far-field anechoic measurement chamber. The measured impedance bandwidths of (reflection coefficient $<-10 \mathrm{~dB}) 12.26 \%(14.3-$ 16.2 GHZ), $8.24 \%(17.4-18.9 \mathrm{GHz})$, and $3.08 \%(19.2-19.8)$ have been achieved through the proposed antenna prototype. $5.9 \mathrm{dBi}$, $3.37 \mathrm{dBi}$, and $3.32 \mathrm{dBi}$ peak gains have been measured and simulated radiation efficiencies of $80.3 \%, 81.9 \%$, and $82.5 \%$ have been achieved at three resonant frequencies of $15.15 \mathrm{GHz}, 18.2 \mathrm{GHz}$, and $19.5 \mathrm{GHz}$, respectively. Minimum gain variation, symmetric, and almost steady measured radiation pattern shows that the proposed antenna is suitable for $\mathrm{Ku}$ and $\mathrm{K}$ band satellite applications.
\end{abstract}

\section{Introduction}

In response to the fast growing microwave technology, there is increasing demand of compact, low profile, low cost, and light weight wireless communication module. In order for the communication terminal to be small, the antennas are needed to be low profile and compact in size [1-3]. Further demand of the planar patch antennas is intensified due to the attractive properties like simple geometric structure, compact, low profile, ease of integration, and fabrication characteristics with wide bandwidth. Nowadays, there is increasing demand of portable wireless communication devices and it is necessary to be dual/multiband compatible to use in different areas or countries. Due to the scarcity of bandwidth in the lower band, $\mathrm{Ku} / \mathrm{K}$ band antenna design receives significant research attention recently $[4,5]$. As a result, the demand of satellite-based portable communication devices is increasing remarkably, especially vehicle tracking, portable satellite station, weather forecasting, and so forth. Numerous types of patch antennas have been studied and examined by several researchers due to their excellent properties. These antennas use the monopole configuration, such as ring, elliptical, circular disc, annual ring, triangle, pentagon, and hexagonal antennas, and the dipole configuration like bow-tie antennas [6-11].

In order to design small and compact wireless device, it is obligatory to miniaturize the antenna size accordingly. There are numbers of requirements such as wide bandwidth, less expensive, miniature size, steady radiation patterns, and consistent gain for multiband antennas [5, 12]. Several studies have reported applications and technologies of the multiband antenna design, including dipole antenna loaded with single-cell metamaterial [13], slot-ring antenna with singleand dual-capacitive coupled patch [14], metamaterial-based planar antenna $[15,16]$, dual-patch elements [6], E-shape fractal antenna [17], and electromagnetic band gap (EBG) structure-based antenna [10]. A numerous concentration has given by several researchers that cutting the printed slot at the edge of radiating patch to create the desired antenna shape with targeted resonant frequency can be obtained $[18,19]$. Although the resonance of the antenna not only depends on 
TABLE 1: Configuration of the proposed patch antenna.

\begin{tabular}{lccc}
\hline Parameter & Value & Parameter & Value \\
\hline$L_{0}$ & $20 \mathrm{~mm}$ & $W_{0}$ & $15 \mathrm{~mm}$ \\
$L_{1}$ & $4 \mathrm{~mm}$ & $W_{1}$ & $2 \mathrm{~mm}$ \\
$L_{2}$ & $2 \mathrm{~mm}$ & $W_{2}$ & $4 \mathrm{~mm}$ \\
$L_{3}$ & $2 \mathrm{~mm}$ & $W_{3}$ & $4 \mathrm{~mm}$ \\
$L_{4}$ & $4 \mathrm{~mm}$ & $W_{4}$ & $2 \mathrm{~mm}$ \\
$L_{5}$ & $5 \mathrm{~mm}$ & $W_{5}$ & $1 \mathrm{~mm}$ \\
\hline
\end{tabular}

the slot but also depends on the size of the radiating element, feed line characteristics, ground plane, and so forth.

Furthermore, a significant amount of research attention has been given into microstrip patch antennas since decades. A $79 \mathrm{~mm} \times 38 \mathrm{~mm}$ EE-H shaped L probe microstrip patch antenna has been introduced and achieved bandwidth $440 \mathrm{MHz}$ with peak gain $9.5 \mathrm{dBi}$ [20]. A $58 \mathrm{~mm} \times 58 \mathrm{~mm}$ wideband dual polarized patch antenna has been proposed and obtained $1.03 \mathrm{GHz}$ bandwidth with $9.3 \mathrm{dBi}$ gain [21]. A $12 \mathrm{~mm} \times 16 \mathrm{~mm}$ ultrawideband antenna with dual notched band characteristics has been offered and achieved $8.3 \mathrm{GHz}$ bandwidth and $3.8 \mathrm{dBi}$ maximum gain [22]. However, the reported antennas are either narrower in bandwidth, lower in gain, or larger in size compared to the proposed antenna. Nonetheless, more research concentration needs to be given to improve gain, efficiency, and bandwidth alongside the miniaturization of overall antenna size.

Therefore, a $20 \mathrm{~mm} \times 15 \mathrm{~mm}$ compact, low profile dual band slotted patch antenna has been designed and prototyped on epoxy polymer resin-based printed circuit board (PCB). The performance of the proposed antenna prototype has been measured in a standard far-field anechoic measurement chamber. The impedance bandwidths (reflection coefficient $<-10 \mathrm{~dB}$ ) ranging from $14.3 \mathrm{GHz}$ to $16.2 \mathrm{GHz}$ $(1.9 \mathrm{GHz})$, from $17.4 \mathrm{GHz}$ to $18.9 \mathrm{GHz}(1.5 \mathrm{GHz})$, and from $19.2 \mathrm{GHz}$ to $19.8 \mathrm{GHz}(0.6 \mathrm{GHz})$ have been measured from the proposed antenna prototype. The gains of $5.9 \mathrm{dBi}, 3.37 \mathrm{dBi}$, and $3.32 \mathrm{dBi}$ have measured and radiation efficiencies of $80.3 \%, 81.9 \%$, and $82.5 \%$ have been simulated at three resonant frequencies of $15.15 \mathrm{GHz}, 18.2 \mathrm{GHz}$, and $19.5 \mathrm{GHz}$, respectively. Radiation characteristics and surface current distribution along the radiating patch are also analyzed in this paper.

\section{Antenna Design and Configurations}

The proposed antenna is designed and analyzed by using finite element method-based high frequency electromagnetic field simulator $[12,23]$. The design configuration starts with $20 \mathrm{~mm}(1.01 \lambda)$ long and $15 \mathrm{~mm}(0.75 \lambda)$ planar slotted $2 \mathrm{~S}$ shape radiating patch. In the proposed antenna design, $\lambda$ is corresponding to the wavelength at the fundamental frequency $15.15 \mathrm{GHz}$. The $2 \mathrm{~S}$ shape is obtained by cutting 4 slots perpendicular to each other from rectangular shape. The size of the radiating patch has a major effect on the antenna performance. The overall size of the proposed antenna has been determined by using widely used mathematical formulation

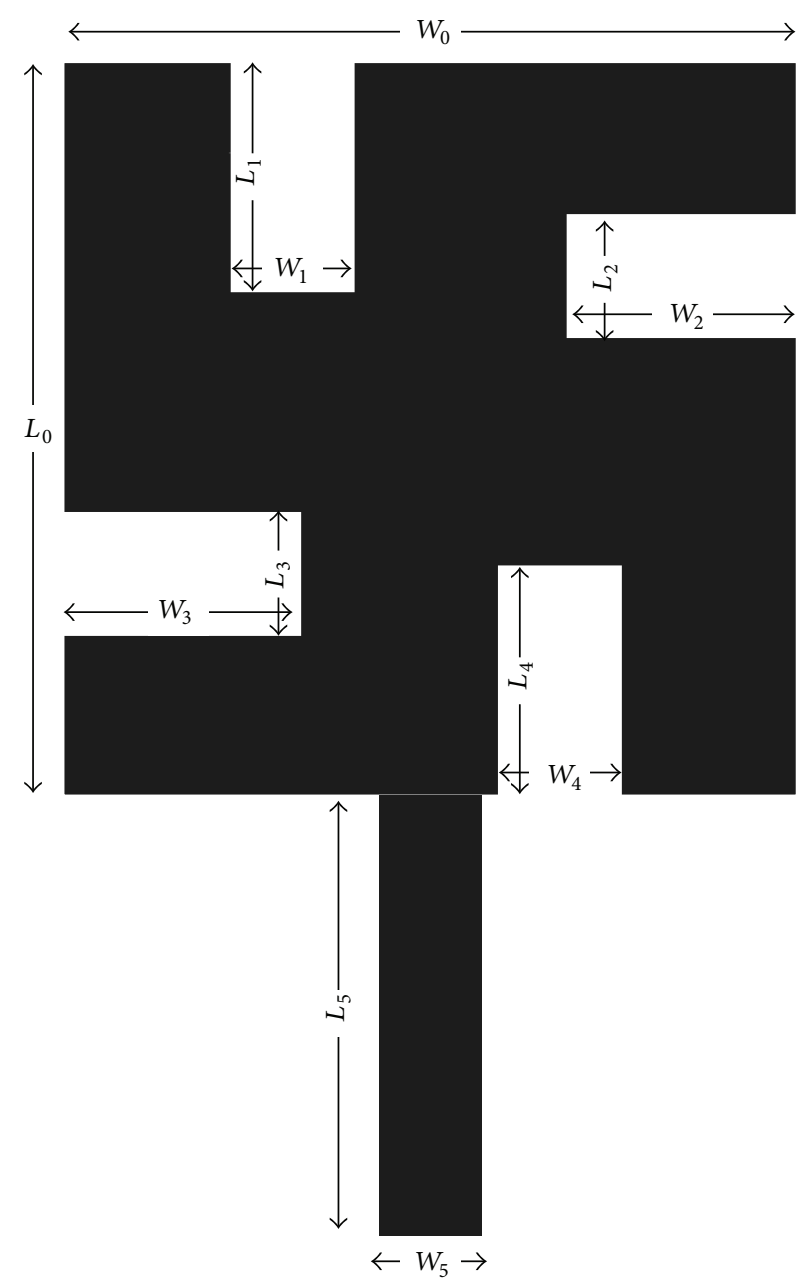

FIGURE 1: Design schematic of the radiating patch of the proposed antenna.

for patch antennas [24]. The available mathematical modeling of patch antennas is based on rectangular patch. Although due to the four cutting slots in radiating patch the overall size calculation is not straightforward as simple rectangular patch antenna, it has been optimized using HFSS optimetrics $[16,25-27]$. The electromagnetic wave propagates toward the endfire direction headed by the parasitic director element on the top while acting as an impedance matching element simultaneously. The design of the microstrip radiating patch element involves the estimation of its dimensions. The patch width $(W)$ has a minor effect on the resonance and it has been determined by using the mathematical modeling as shown below [24]:

$$
W=\frac{c}{2 f_{o}} \sqrt{\frac{\varepsilon_{r}+1}{2}}
$$

where $c$ is the speed of light in free space and $\varepsilon_{r}$ is the relative permittivity of the substrate material of the proposed antenna. The microstrip patch lies between air and 

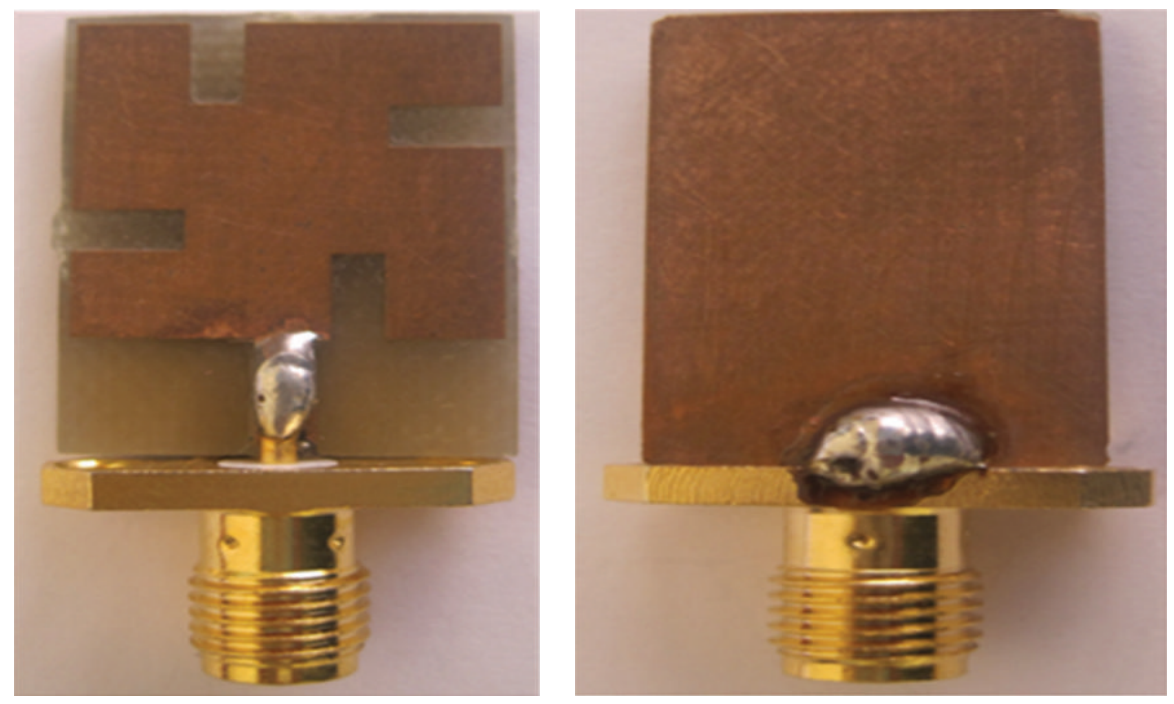

FIGURE 2: Photograph of the proposed antenna prototype top view and rear view, respectively.

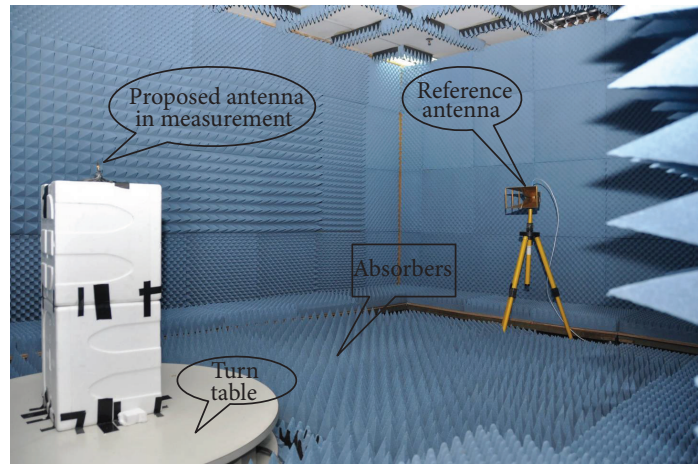

FIGURE 3: Illustration of the anechoic measurement chamber.

the dielectric material, and, thus, the electromagnetic wave sees an effective permittivity $\left(\varepsilon_{\text {ref }}\right)$ given by [24]:

$$
\varepsilon_{\mathrm{reff}}=\left[\frac{\varepsilon_{r}+1}{2}\right]+\left[\frac{\varepsilon_{r}-1}{2}\right] \sqrt{\left[1+\frac{10 h}{W}\right]} .
$$

The length of the radiating patch $(L)$ is responsible for the resonant frequency and is a critical parameter in design because of the inherent narrow bandwidth of the patch. The design value for $L$ can be determined by using the following formula [24]:

$$
L=\frac{c}{2 f_{o} \sqrt{\varepsilon_{\text {reff }}}}-2 \Delta l,
$$

where $\varepsilon_{\text {reff }}$ is the effective permittivity of the substrate material of the proposed antenna. The additional line length on $\Delta L$ both ends of the patch length, due to the effect of fringing fields, is given by [3]

$$
\frac{\Delta L}{h}=0.412\left[\frac{\left(\varepsilon_{\text {reff }}+0.3\right)}{\left(\varepsilon_{\text {reff }}+0.3\right)}\right]\left[\frac{\omega / h+0.264}{\omega / h+0.8}\right] .
$$

The effective patch length $L_{e}$ can be written as [20]

$$
L_{e}=1+2 \Delta l \text {. }
$$

The proposed antenna fed by $2 \mathrm{~mm}$ long $1 \mathrm{~mm}$ wide widely used microstrip feed line to achieve impedance characteristics of $50 \mathrm{ohm}$. An SMA connector is connected at the end of the microstrip feed line. The design geometry of the proposed antenna has shown in Figure 1. The length of the radiating patch dominates bandwidth and resonance, whereas the width has minor effect. The microstrip feed line with $5 \mathrm{~mm} \times 1 \mathrm{~mm}$ dimension is placed at the center of $Y$-axis to achieve $50 \mathrm{ohm}$ impedance characteristics. The details of the proposed antenna configuration are tabulated in Table 1 .

The schematic of the radiating patch of the proposed antenna has been shown in Figure 1 and the detail configuration. The proposed antenna is printed on more available, low cost, durable epoxy polymer resin material substrate with thickness of $1.6 \mathrm{~mm}$, relative permittivity of 4.6 , dielectric loss tangent of 0.02 , using in-house S63 PCB prototyping machine from LPKF, Garbsen, Germany. At the end of the microstrip feed line, SMA connector is connected. The fabricated prototype of the proposed antenna is illustrated in Figure 2.

\section{Measurement Environment}

The prototype of the proposed antenna has been measured in a standard far-field testing environment $[18,28]$. A rectangular shape $5.5 \times 4.5 \mathrm{~m}^{2}$ and $4 \mathrm{~m}$ height anechoic measurement chamber were used to measure the result parameter of the proposed antenna prototype. A double ridge guide horn antenna has been used as reference antenna. Pyramidal shape electrically thick foam absorber with less than $-60 \mathrm{~dB}$ reflectivity at normal incidence has been used on the wall, celling and floor. A turn table of $1.2 \mathrm{~m}$ diameter has been used 


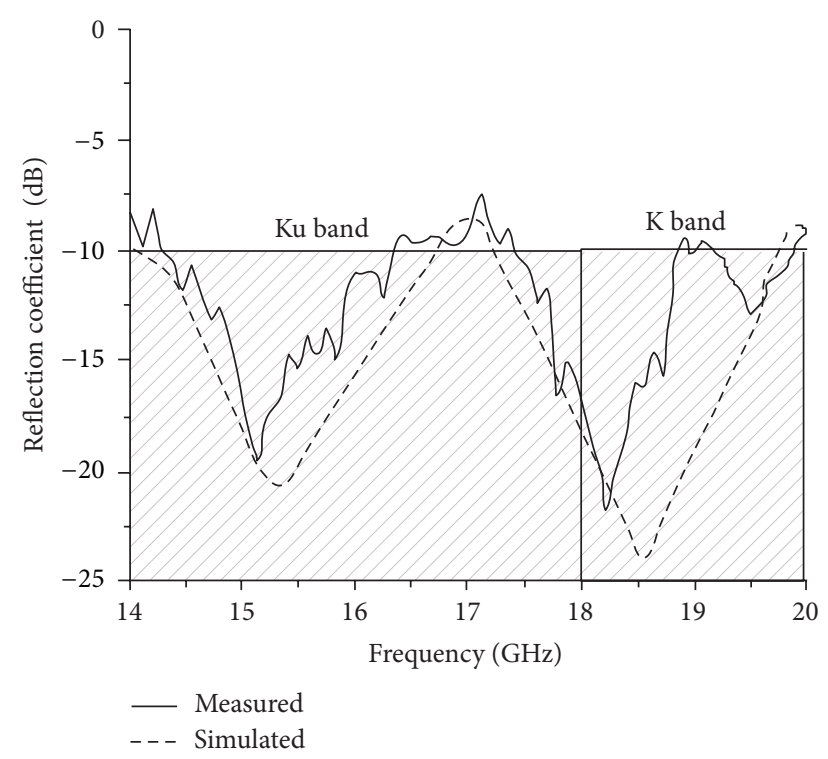

FIgURE 4: Simulated and measured reflection coefficients of the proposed antenna prototype.

to rotate the measuring antenna with specification, $1 \mathrm{rpm}$ rotation speed; $360^{\circ}$ rotation angle connected with 10 meter cable between controllers. An Agilent PNA-series vector network analyzer (Agilent E8362C) ranging up to $20 \mathrm{GHz}$ has been used for measurement procedure. Figure 3 shows the photograph of the anechoic antenna measurement chamber.

\section{Performance Result and Discussion}

The performance results of the proposed antenna prototype are deliberated in this section. The measured and simulated reflection coefficients are shown in Figure 4. It can be clearly seen that the impedance bandwidth (reflection coefficient $<-10 \mathrm{~dB}$ ) ranging from $14.3 \mathrm{GHz}$ to $16.2 \mathrm{GHz}$ $(1.9 \mathrm{GHz})$, from $17.4 \mathrm{GHz}$ to $18.9 \mathrm{GHz}(1.5 \mathrm{GHz})$, and from $19.3 \mathrm{GHz}$ to $19.8 \mathrm{GHz}(0.6 \mathrm{GHz})$ was measured from the proposed antenna prototype. The slight inconsistency observed between simulated and measured reflection coefficients could be due to SMA soldering effect or the loss introduced by the cable between antenna under test and the controller. However, the measurement setup has been calibrated using Agilent automatic calibration tools. The simulated and measured gain of the proposed antenna has been shown in Figure 5. Average gains of $5.6 \mathrm{dBi}, 3.5 \mathrm{dBi}$, and $3.1 \mathrm{dBi}$ have been measured for first, second, and third bands correspondingly. For the gain measurement of the proposed antenna, three antenna measurement systems have been used with two identical horn antennas $[29,30]$.

The radiation efficiency of the proposed antenna is shown in Figure 6. It exhibits $80.3 \%, 81.9 \%$, and $82.5 \%$ at three resonant frequencies of $15.15 \mathrm{GHz}, 18.2 \mathrm{GHz}$, and $19.5 \mathrm{GHz}$, respectively, with minimum variation. The measured almost steady radiation pattern of the proposed antenna prototype is shown in Figure 7. The cross polarization effects of both

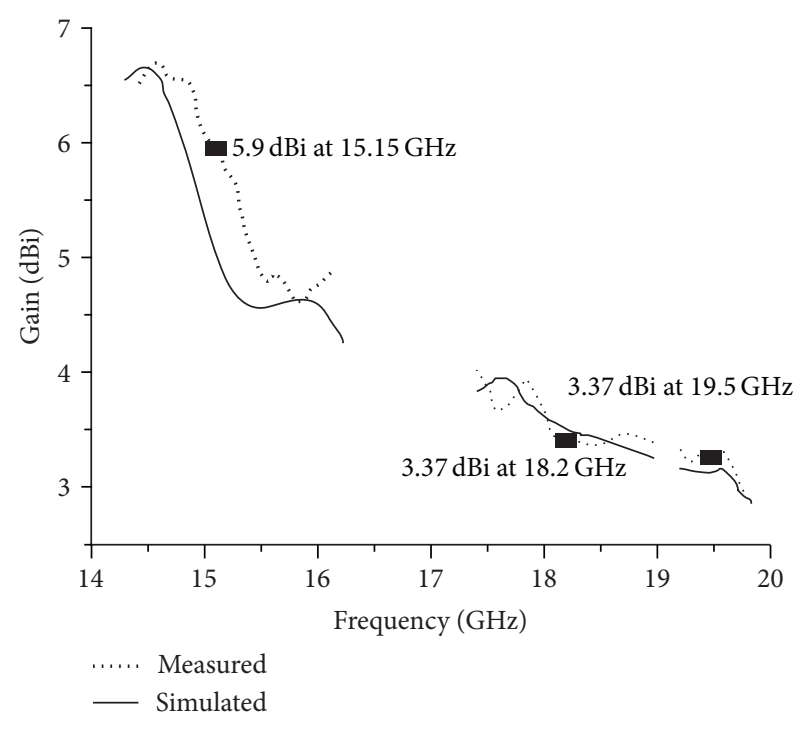

FIGURE 5: Simulated and measured gains of the proposed antenna.

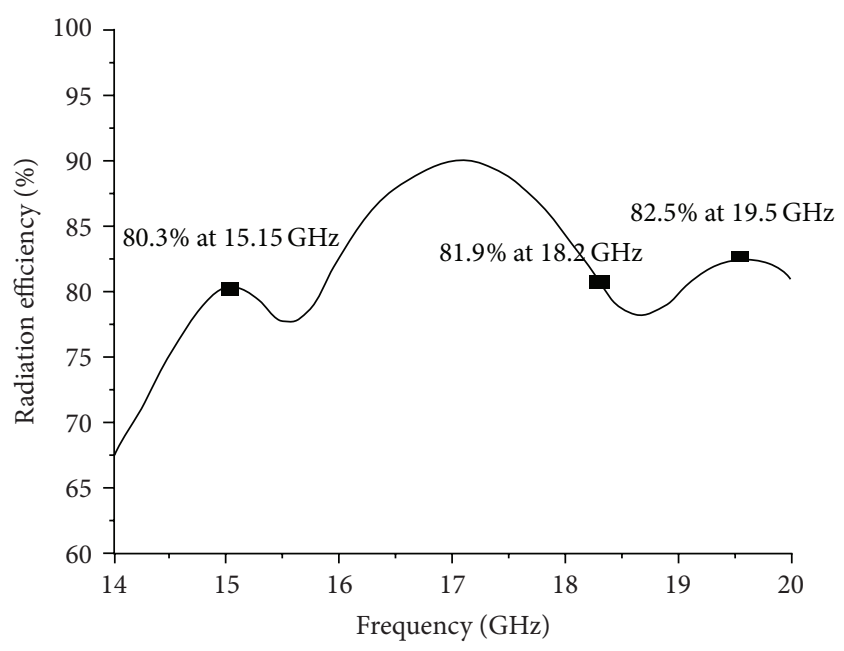

FIGURE 6: Radiation efficiency of the proposed antenna.

$\mathrm{E}$ and $\mathrm{H}$ planes are lower than copolarization. Figure 8 shows the Smith chart of the proposed antenna. The VSWR and impedance $(\mathrm{Rx})$ characteristics can be validated from the Smith chart. It can be clearly observed that the three resonant frequencies are in the VSWR 2:1 circle.

\section{Conclusion}

A $20 \mathrm{~mm} \times 15 \mathrm{~mm}$ slotted patch antenna was designed and fabricated on the epoxy polymer resin composite material substrate for dual band applications. The measured performance results of the proposed antenna exhibit the impedance bandwidth (reflection coefficient $<-10 \mathrm{~dB}$ ) ranging from $14.3 \mathrm{GHz}$ to $16.2 \mathrm{GHz}(12.26 \%)$, from $17.4 \mathrm{GHz}$ to $18.9 \mathrm{GHz}(8.24 \%)$, and from $19.3 \mathrm{GHz}$ to $19.8 \mathrm{GHz}(3.08 \%)$. 

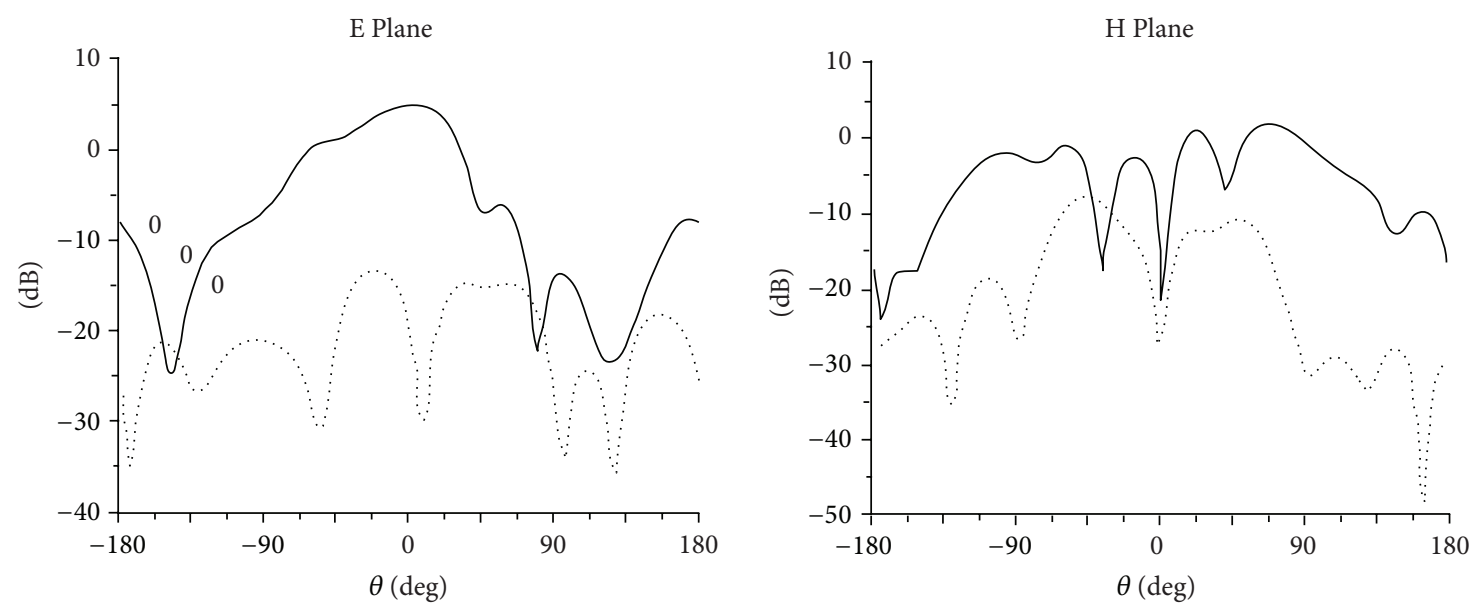

(a)
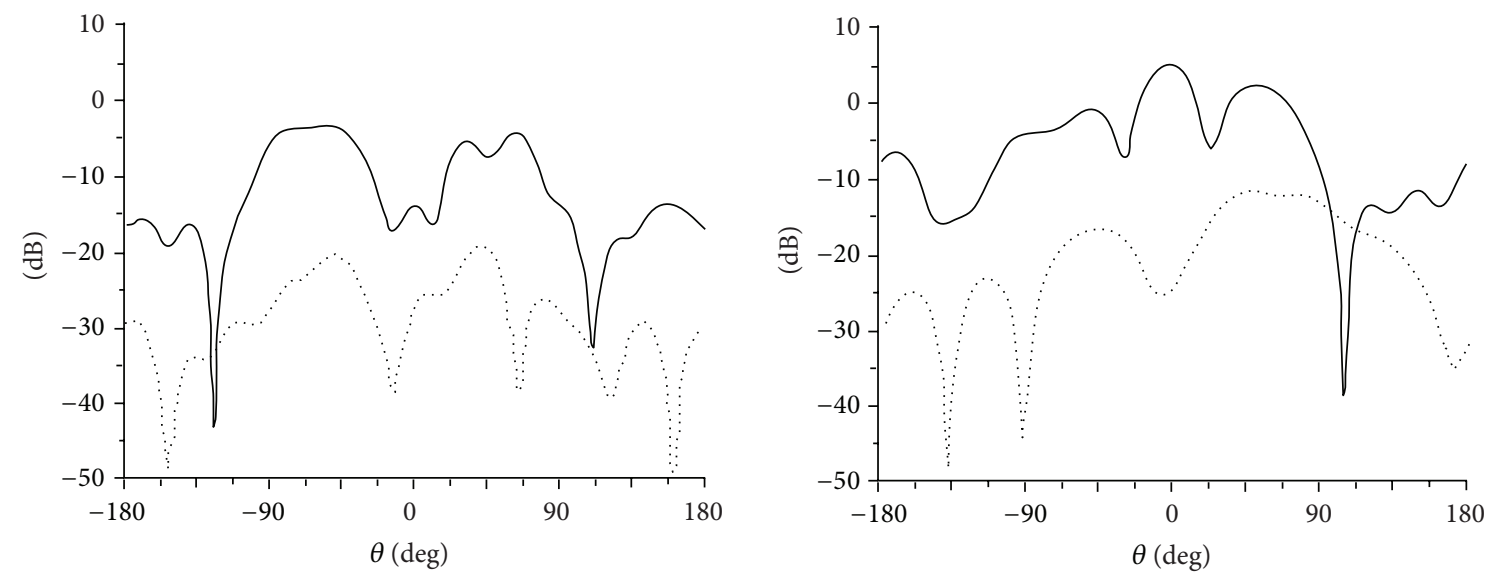

(b)
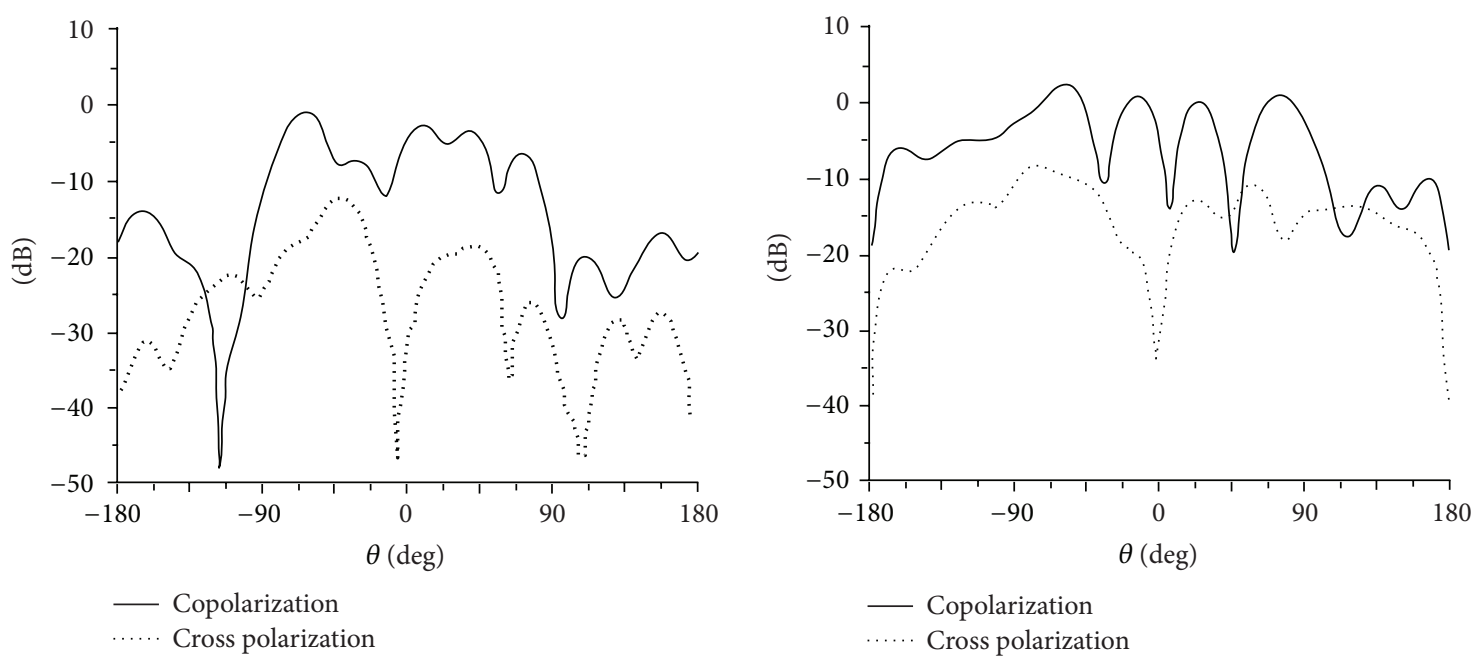

(c)

FIGURE 7: Measured radiation pattern of the proposed antenna at (a) $15.15 \mathrm{GHz}$, (b) $18.2 \mathrm{GHz}$, and (c) $19.5 \mathrm{GHz}$. 


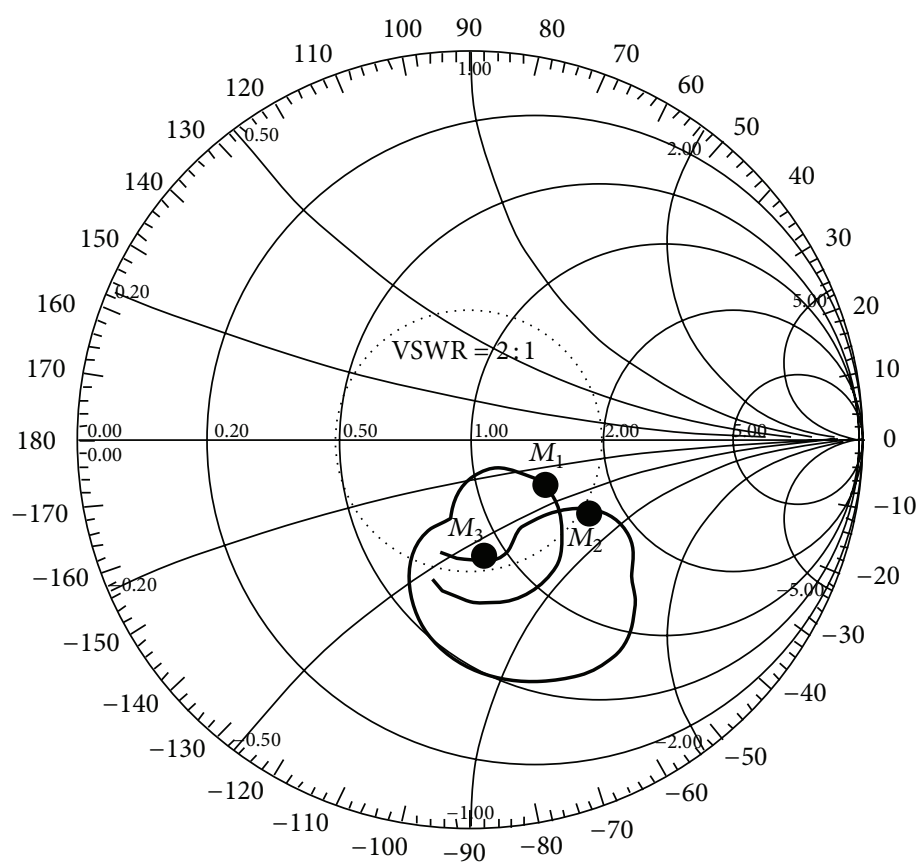

\begin{tabular}{|c|c|c|c|}
\hline Mark & $\begin{array}{c}\text { Freq. } \\
(\mathrm{GHz})\end{array}$ & $\mathrm{Rx}$ & VSWR \\
\hline$M_{1}$ & 15.15 & $0.985-0.781 i$ & 1.65 \\
\hline$M_{2}$ & 18.2 & $1.042-0.892 i$ & 1.892 \\
\hline$M_{3}$ & 19.5 & $1.245-0.967 i$ & 1.901 \\
\hline
\end{tabular}

FIGURE 8: The Smith chart of the proposed antenna.

Average gains of $5.6 \mathrm{dBi}, 3.5 \mathrm{dBi}$, and $3.1 \mathrm{dBi}$ have been measured at first, second, and third bands, respectively. Radiation efficiencies of $80.3 \%, 81.9 \%$, and $82.5 \%$ have been simulated at three resonant frequencies of $15.15 \mathrm{GHz}, 18.2 \mathrm{GHz}$, and $19.5 \mathrm{GHz}$ correspondingly. The measured almost steady omnidirectional radiation pattern shows that the proposed antenna is suitable for $\mathrm{Ku}$ and $\mathrm{K}$ band applications.

\section{Conflict of Interests}

The authors declare that there is no conflict of interests regarding the publication of this paper.

\section{References}

[1] Y. Cao, B. Yuan, and G. Wang, "A compact multiband openended slot antenna for mobile handsets," IEEE Antennas and Wireless Propagation Letters, vol. 10, pp. 911-914, 2011.

[2] M. T. Islam, M. Moniruzzaman, N. Misran, and M. N. Shakib, "Curve fitting based particle swarm optimization for uwb patch Antenna," Journal of Electromagnetic Waves and Applications, vol. 23, no. 17-18, pp. 2421-2432, 2009.
[3] M. Habib Ullah, M. T. Islam, J. S. Mandeep, N. Misran, and N. Nikabdullah, "A compact wideband antenna on dielectric material substrate for K band," Electronics and Electrical Engineering, vol. 123, no. 7, pp. 75-79, 2012.

[4] M. H. Ullah, M. T. Islam, and J. S. Mandeep, "Printed prototype of a wideband S-shape microstrip patch antenna for $\mathrm{Ku} / \mathrm{K}$ band applications," Applied Computational Electromagnetics Society Journal, vol. 28, no. 4, pp. 307-313, 2013.

[5] R. Azim, M. T. Islam, and N. Misran, "Printed planar antenna for wideband applications," Journal of Infrared, Millimeter, and Terahertz Waves, vol. 31, no. 8, pp. 969-978, 2010.

[6] H. F. Abutarboush, R. Nilavalan, S. W. Cheung et al., "A reconfigurable wideband and multiband antenna using dualpatch elements for compact wireless devices," IEEE Transactions on Antennas and Propagation, vol. 60, no. 1, pp. 36-43, 2012.

[7] L. Liu, S. W. Cheung, R. Azim, and M. T. Islam, "A compact circular-ring antenna for ultra-wideband applications," Microwave and Optical Technology Letters, vol. 53, no. 10, pp. 2283-2288, 2011.

[8] S. K. Rajgopal and S. K. Sharma, "Investigations on ultrawideband pentagon shape microstrip slot antenna for wireless communications," IEEE Transactions on Antennas and Propagation, vol. 57, no. 5, pp. 1353-1359, 2009. 
[9] J. J. Tiang, M. T. Islam, N. Misran, and J. S. Mandeep, "Slot loaded circular microstrip antenna with meandered slits," Journal of Electromagnetic Waves and Applications, vol. 25, no. 13, pp. 1851-1862, 2011.

[10] T. Li, H. Q. Zhai, G. H. Li, and C. H. Liang, "Design of compact UWB band-notched antenna by means of electromagneticbandgap structures," Electronics Letters, vol. 48, no. 11, pp. 608609, 2012.

[11] J. Yang and A. Kishk, "A novel low-profile compact directional ultra-wideband antenna: the self-grounded Bow-Tie antenna," IEEE Transactions on Antennas and Propagation, vol. 60, no. 3, pp. 1214-1220, 2012.

[12] M. H. Ullah, M. T. Islam, J. S. Mandeep, and N. Misran, "A new double $\mathrm{L}$ shape multiband patch antenna on polymer resin material substrate," Applied Physics A, vol. 110, no. 1, pp. 199-205, 2013.

[13] M. R. Booket, A. Jafargholi, M. Kamyab, H. Eskandari, M. Veysi, and S. M. Mousavi, "Compact multi-band printed dipole antenna loaded with single-cell metamaterial," IET Microwaves, Antennas and Propagation, vol. 6, no. 1, pp. 17-23, 2012.

[14] C. Y. Sim, F. R. Cai, and Y. P. Hsieh, "Multiband slotring antenna with single- and dual-capacitive coupled patch for wireless local area network/worldwide interoperability for microwave access operation," IET Microwaves, Antennas and Propagation, vol. 5, no. 15, pp. 1830-1835, 2011.

[15] D. K. Ntaikos, N. K. Bourgis, and T. V. Yioultsis, "Metamaterialbased electrically small multiband planar monopole antennas," IEEE Antennas and Wireless Propagation Letters, vol. 10, pp. 963-966, 2011.

[16] Y. Rahmat-Samii, L. I. Williams, and R. G. Yaccarino, "UCLA bi-polar planar-near-field antenna-measurement and diagnostics range," IEEE Antennas and Propagation Magazine, vol. 37, no. 6, pp. 16-35, 1995.

[17] F. A. Ghaffar, M. U. Khalid, K. N. Salama, and A. Shamim, "24$\mathrm{GHz}$ LTCC fractal antenna array SoP with integrated Fresnel lens," IEEE Antennas and Wireless Propagation Letters, vol. 10, pp. 705-708, 2011.

[18] M. H. Ullah and M. T. Islam, "A compact square loop patch antenna on high dielectric ceramic-PTFE composite material," Applied Physics A, vol. 113, no. 1, pp. 185-193, 2013.

[19] M. Bittera, J. Hallon, and V. Smieško, "Measurement and simulation of field homogenity inside semi-anechoic chamber," in Measurement Science Review, vol. 3, section 3, pp. 143-146, 2003.

[20] M. T. Islam, M. N. Shakib, and N. Misran, "Design analysis of high gain wideband L-probe fed microstrip patch antenna," Progress in Electromagnetics Research, vol. 95, pp. 397-407, 2009.

[21] B. Li, Y.-Z. Yin, W. Hu, Y. Ding, and Y. Zhao, "Wideband dualpolarized patch antenna with low cross polarization and high isolation," IEEE Antennas and Wireless Propagation Letters, vol. 11, pp. 427-430, 2012.

[22] M. Moosazadeh, A. M. Abbosh, and Z. Esmati, "Design of compact planar ultrawideband antenna with dual-notched bands using slotted square patch and pi-shaped conductor-backed plane," IET Microwaves, Antennas and Propagation, vol. 6, no. 3, pp. 290-294, 2012.

[23] M. H. Ullah and M. T. Islam, "Ceramic substrate shrinks patch antenna," Microwaves and RF, vol. 51, no. 8, pp. 50-54, 2012.

[24] C. A. Balanis, Antenna Theory: Analysis and Design, Wiley-Interscience, 3rd edition, 2012.

[25] R. T. Remski, "Analysis of photonic bandgap surfaces using Ansoft HFSS," Microwave Journal, vol. 43, no. 9, pp. 190-198, 2000.
[26] N. Appannagaari, I. Bardi, R. Edlinger et al., "Modeling phased array antennas in Ansoft HFSS," in Proceedings of the IEEE International Conference on Phased Array Systems and Technology, pp. 323-326, May 2000.

[27] R. T. Remski, "Analysis of photonic bandgap surfaces using Ansoft HFSS," Microwave Journal, vol. 43, no. 9, pp. 190-198, 2000.

[28] "IEEE Standard Test Procedures for Antennas," ANSI/IEEE Standard 149-1979, pp. 94-96, 1979.

[29] G. E. Evans, Antenna Measurement Techniques, vol. 1, Artech House, Norwood, NJ, USA, 1990.

[30] M. H. Ullah, M. T. Islam, and M. R. I. Faruque, "A nearzero refractive index meta-surface structure for antenna performance improvement," Materials, vol. 6, no. 11, pp. 5058-5068, 2013. 

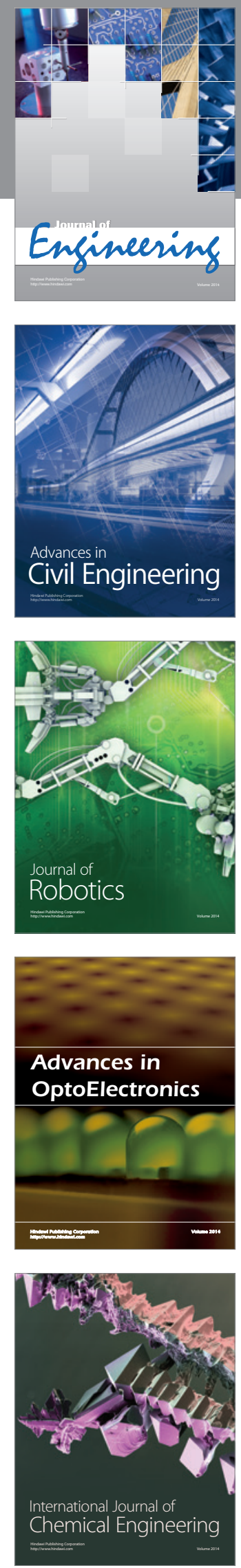

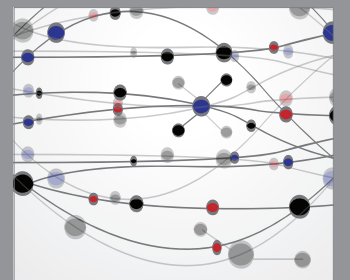

The Scientific World Journal
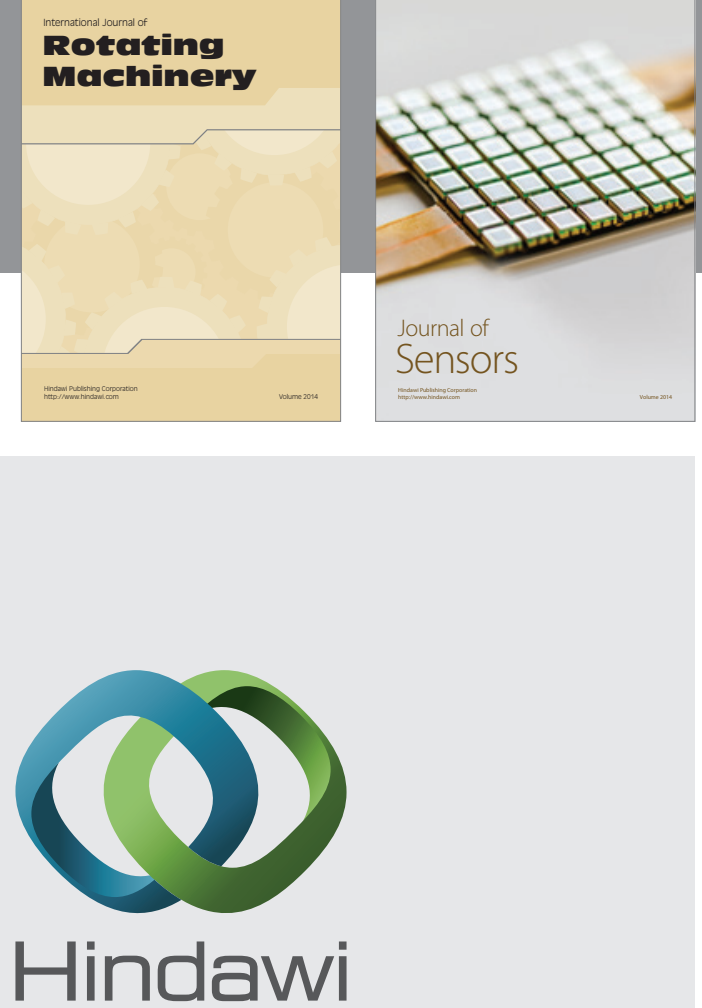

Submit your manuscripts at http://www.hindawi.com
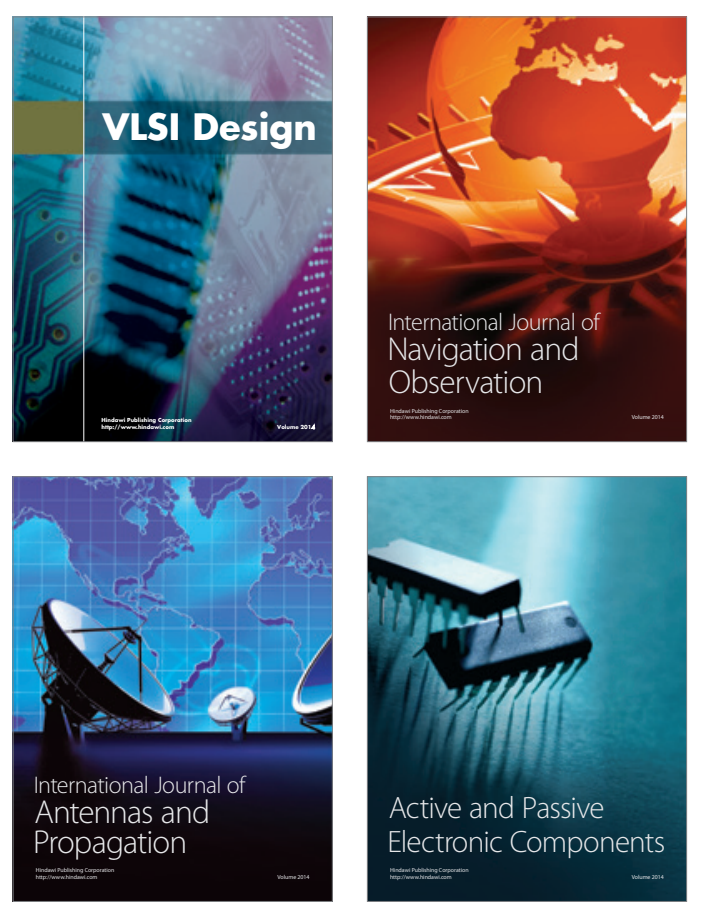
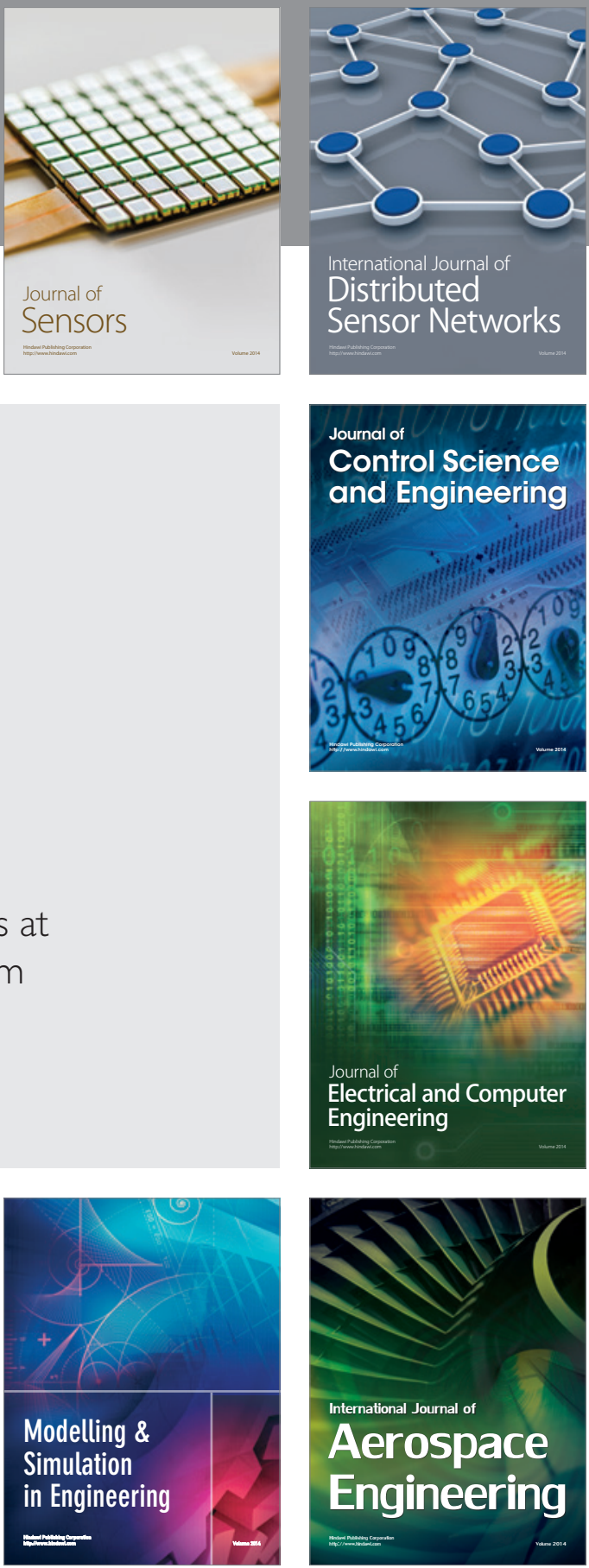

Journal of

Control Science

and Engineering
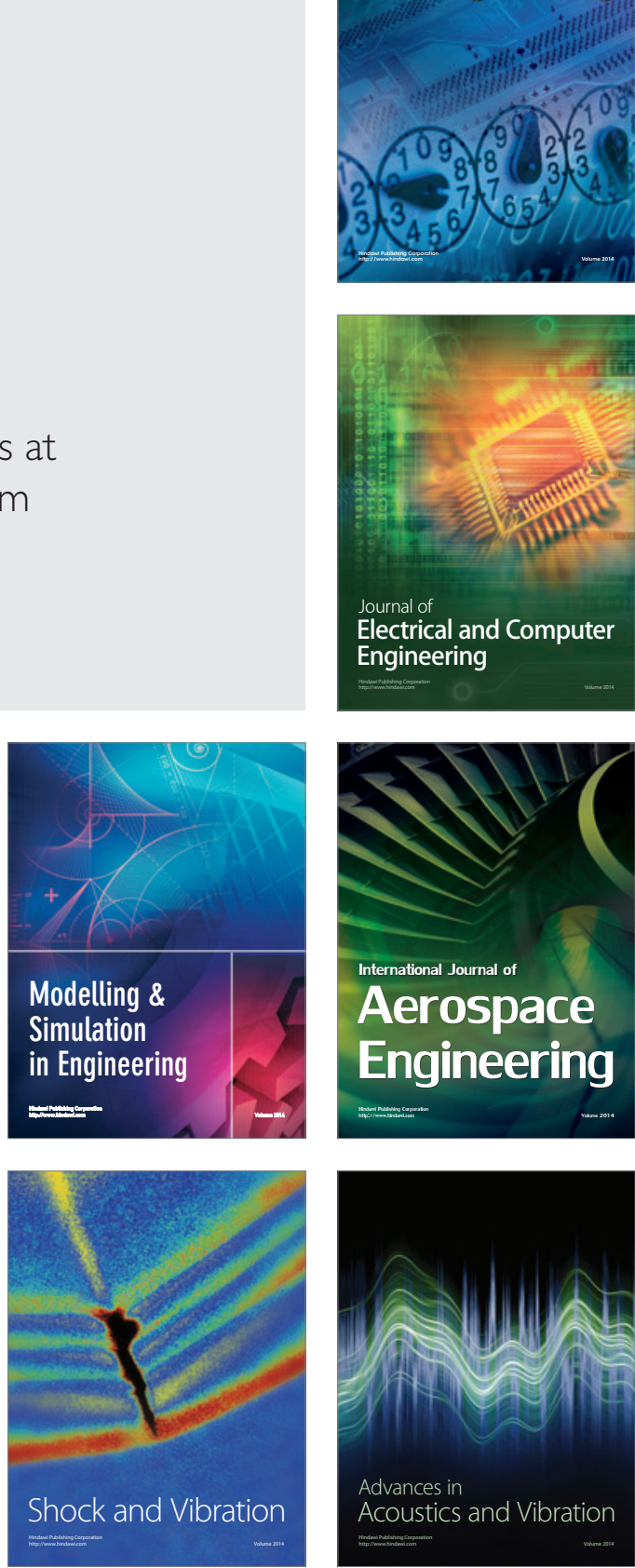